\title{
THE ANALYSIS OF SCREENING COSTS FOR HYPERCHOLESTEROLEMIA AND HYPERGLYCEMIA AS PART OF OBLIGATORY EXAMINATIONS OF EMPLOYEES
}

\author{
ANDRZEJ MARCINKIEWICZ ${ }^{1,2}$, DOMINIK OLEJNICZAK ${ }^{2,3}$, DANIEL ŚLIŻ ${ }^{2,4,5}$, and ANNA STANISZEWSKA \\ ${ }^{1}$ Nofer Institute of Occupational Medicine, Łódź, Poland \\ Department of Occupational Diseases and Environmental Health \\ ${ }^{2}$ Public Health Committee of the Polish Academy of Sciences, Warsaw, Poland \\ ${ }^{3}$ Medical University of Warsaw, Warsaw, Poland \\ Department of Public Health \\ ${ }^{4}$ Medical University of Warsaw, Warsaw, Poland \\ 3rd Department of Internal Diseases and Cardiology, 2nd Faculty of Medicine \\ ${ }^{5}$ Centre of Postgraduate Medical Education in Warsaw, Warsaw, Poland \\ School of Public Health \\ ${ }^{6}$ Medical University of Warsaw, Warsaw, Poland \\ Department of Experimental and Clinical Pharmacology \\ ${ }^{7}$ Committee on Therapeutics and Pharmaceuticals Science of the Polish Academy of Sciences, Warsaw, Poland
}

\begin{abstract}
Objectives: High prevalence of hyperlipidemia and hyperglycemia requires searching for efficient and cost-effective methods of an early detection of these disorders. In Poland, obligatory employee medical check-ups could be a solution. Material and Methods: The study included a group of university employees who underwent obligatory occupational examinations in 2018. Each employee had an additional lipid (unit cost: EUR 2.56) and blood glucose profile (EUR 0.93) done. The number of respondents involved in the study was 850 (340 males and 510 females), and their average age was 47 years ( $\mathrm{SD}=11$ years). The education distribution was as follows: employees with secondary vocational and general education (physical, frontline and administrative workers): 176 (age: $\mathrm{M} \pm$ SD 50.3 \pm 10.3 ); employees with a university degree (academics with an M.Sc. or/and Ph.D. title and administrative staff): 535 (age: $\mathrm{M} \pm \mathrm{SD} 43.6 \pm 9.8$ ); and academics with a university title (Ass. Prof. and/or Prof.): 139 (age: M \pm SD 56.2 \pm 10.2 ). Results: Dyslipidemia (elevated total cholesterol $\geq 190 \mathrm{mg} / \mathrm{dl}$ and/or low-density lipoprotein cholesterol $\geq 115 \mathrm{mg} / \mathrm{dl}$ ) was reported in $560 \mathrm{workers}$ $(65.9 \%)$ ). Hyperglycemia (fasting glucose $\geq 100 \mathrm{mg} / \mathrm{dl}$ ) was observed in 256 workers $(31 \%)$ ). The total cost of detecting a single case of dyslipidemia and hyperglycemia was EUR 3.88 and EUR 3.09, respectively. Divided by age groups, the costs were as follows: EUR 4.34 and EUR 4.53 in the age group $<45$ years; EUR 3.56 and EUR 2.42 in the age group $\geq 45$ years. The costs of detecting a single case of dyslipidemia and hyperglycemia in employees aged $\geq 45$ with regard to education were as follows: EUR 3.20 and EUR 2.07 in persons with secondary vocational and general education; EUR 3.40 and EUR 2.80 in persons with a university degree; and EUR 4.38 and EUR 2.28 in persons with a university title. Conclusions: Due to the fact that the reporting rate for screening tests in the framework of occupational medicine is high, the cost of occupational screening tests for dyslipidemia and hyperglycemia can be lower than the cost of screening tests in the general population. Int J Occup Med Environ Health. 2021;34(5):581-9
\end{abstract}

Key words:

screening, dyslipidemia, cost-effectiveness, economic evaluation, hyperglycemia, occupational health programs

Received: August 21, 2020. Accepted: December 10, 2020.

Corresponding author: Andrzej Marcinkiewicz, Nofer Institute of Occupational Medicine, Department of Occupational Diseases and Environmental Health, św. Teresy 8 , 91-348 Łódź, Poland (e-mail: andrzej.marcinkiewicz@imp.lodz.pl). 


\section{INTRODUCTION}

High prevalence of hyperlipidemia and hyperglycemia indicates the necessity to use the already available systemic health care solutions to implement effective preventive measures aimed at an early detection of cardiovascular diseases and diabetes, and increasing general awareness of the risk related to these diseases. Special attention should be focused on the labor force, especially in the context of the aging of working populations and occupational risk factors for cardiovascular diseases and diabetes. Numerous examples presented in scientific literature show that occupational health programs can not only improve workers' health, but also bring significant savings in both short and long term [1]. A multicenter study in Europe, North America and Australia revealed that an investment of EUR 1 in occupational health can be recouped in the amount of EUR 2.2 as well as bring additional benefits including increased safety and a better health condition of workers [2]. The basic problem related to the publicly funded health prevention programs in Poland is the insufficient reporting rate, even though these programs are free of charge [3]. A solution could be an effective use of obligatory periodic occupational examinations, which are performed in 5 million workers annually in the 12-million population of the employed [4]. Administratively imposed occupational examinations require a worker to visit a health center, thus creating an opportunity to do a number of screening tests.

The current, legally regulated scope of mandatory occupational examinations does not cover the lipid and blood glucose profiles [5], and including these tests requires cooperation between an employer, an occupational health center and an employee. The employer has to finance these tests, the employee has to report to the health center on an empty stomach, and the medical facility has to adopt a proper procedure.

Health programs aimed at an early detection of diseases should be validated following 2 basic criteria: efficacy expressed as the number of detected disease cases, and cost-effectiveness understood as the health program cost per 1 detected disease case.

The aim of the study was to evaluate the efficacy and costeffectiveness of hypercholesterolemia and hyperglycemia detection in university employees by means of obligatory occupational screening tests.

\section{MATERIAL AND METHODS}

The authors analyzed the effects of a 1-year occupational screening program aimed at detecting hypercholesterolemia and hyperglycemia. The study included all employees of a university in Łódź, who obligatorily underwent occupational examinations in 2018.

The analysis was based on data obtained from 850 study participants (340 males and 510 females), their average age being 47 years ( $\mathrm{SD}=11$ years). The following 3 subgroups were distinguished with regard to the educational status of those included in the study:

- employees with secondary vocational and general education (physical, frontline and administrative workers) - 176 persons (age: $\mathrm{M} \pm$ SD 50.3 \pm 10.3 );

- employees with a university degree (academics with an M.Sc. or/and Ph.D. title and administrative staff) 535 persons (age: $\mathrm{M} \pm$ SD 43.6 \pm 9.8 );

- academics with a university title (Ass. Prof. and/or Prof.) 39 persons (age: $\mathrm{M} \pm$ SD 56.2 \pm 10.2 ).

Every employee who reported to the health center with a referral issued by the university underwent an obligatory occupational examination whose scope was extended with the lipid profile and a fasting plasma glucose (FPG) test. Employees had been informed by the referring body about the necessity to appear for the examination on an empty stomach. This information was also written down on the referral. After the examination, each employee received the results, interpretation of the results and recommendations (e.g., follow-up examinations, lifestyle changes, treatment). Laboratory tests were performed 
on a fasting blood sample in an accredited laboratory. The concentration of low-density lipoprotein (LDL) cholesterol was calculated with the Friedewald formula. Dyslipidemia was established based on the criteria indicated in the Sopot Declaration [6].

The $\chi^{2}$ test was used to compare the proportions in the subgroups. The analysis was performed using TIBCO Software Inc. (2017) Statistica (data analysis software system) v. 13.

The exchange rate of EUR $1=$ PLN 4.3 was adopted in the cost calculation.

The study was approved by the Bioethics Committee of the Nofer Institute of Occupational Medicine in Łódź (Resolution No. 04/2015 of February 18, 2015).

\section{RESULTS}

\section{Efficacy of dyslipidemia and hyperglycemia detection}

The number of detected dyslipidemia cases, i.e., elevated total cholesterol $\geq 190 \mathrm{mg} / \mathrm{dl}(4.9 \mathrm{mmol} / \mathrm{l})$ and/or LDL cholesterol $\geq 115 \mathrm{mg} / \mathrm{dl}(3 \mathrm{mmol} / \mathrm{l})$, and also the number of detected hyperglycemia cases, i.e., fasting glucose $\geq 100 \mathrm{mg} / \mathrm{dl}(5.6 \mathrm{mmol} / \mathrm{l})$, are presented in Table 1 by education and age.

In the calculation of the efficacy of hyperglycemia detection, only persons with no previous diagnosis of diabetes were included. A total of 23 employees (2.7\%) had been previously diagnosed with diabetes, including 4 persons with secondary vocational or general education, 11 persons with higher education, and 8 senior academics. Apart from 5 persons with higher education, the diabetics were aged $>45$ years.

A statistically significant, higher incidence of dyslipidemia and hyperglycemia in employees aged $\geq 45$ years was observed among employees with secondary vocational or general education, and among those with a university degree.

\section{Cost-effectiveness of dyslipidemia}

and hyperglycemia detection

In the analyzed study, the unit cost of the lipid profile was PLN 11.00 (EUR 2.56), and the unit cost of blood glucose profile was PLN 4.00 (EUR 0.93).

Table 1. Dyslipidemia (total cholesterol $\geq 190 \mathrm{mg} / \mathrm{dl}$ and/or low-density lipoprotein cholesterol $\geq 115 \mathrm{mg} / \mathrm{dl}$ ) and hyperglycemia cases (fasting glucose $\geq 100 \mathrm{mg} / \mathrm{dl}$ ) in a group of university employees who underwent obligatory occupational examinations in 2018, Łódź, Poland

\begin{tabular}{|c|c|c|c|c|c|c|c|}
\hline \multirow{3}{*}{ Variable } & \multicolumn{7}{|c|}{$\begin{array}{c}\text { Participants } \\
(\mathrm{N}=850)\end{array}$} \\
\hline & \multicolumn{2}{|c|}{$\begin{array}{l}\text { secondary vocational } \\
\text { or general education } \\
\qquad(\mathrm{N}=176)\end{array}$} & \multicolumn{2}{|c|}{$\begin{array}{l}\text { university degree } \\
\qquad(\mathrm{N}=535)\end{array}$} & \multicolumn{2}{|c|}{$\begin{array}{l}\text { university title } \\
\qquad(\mathrm{N}=139)\end{array}$} & \multirow{2}{*}{$\begin{array}{l}\text { total } \\
\mathrm{n}(\%)\end{array}$} \\
\hline & $\mathrm{n}(\%)$ & $\mathrm{p}$ & $\mathrm{n}(\%)$ & $\mathrm{p}$ & $\mathrm{n}(\%)$ & $\mathrm{p}$ & \\
\hline \multicolumn{8}{|c|}{ Dyslipidemia in the age group } \\
\hline$<45$ years & $36(64.3)$ & 0.02 & $186(57.4)$ & $<0.001$ & $10(71.4)$ & 0.35 & $232(58.9)$ \\
\hline$\geq 45$ years & $96(80)$ & 0.02 & $159(75.4)$ & $<0.001$ & $73(58.4)$ & 0.35 & $328(71.9)$ \\
\hline total & $132(75)$ & - & $345(64.5)$ & - & $83(59.7)$ & - & $560(65.9)$ \\
\hline \multicolumn{8}{|c|}{ Hyperglycemia in the age group } \\
\hline$<45$ years & $14(25)$ & 0.01 & $63(19.7)$ & 0.0003 & $4(28.6)$ & 0.37 & $81(20.8)$ \\
\hline$\geq 45$ years & $54(46.6)$ & 0.01 & $70(34.1)$ & 0.0003 & $51(43.6)$ & 0.37 & $175(40)$ \\
\hline total & $68(39.5)$ & - & $133(25.4)$ & - & $55(42)$ & - & $256(31)$ \\
\hline
\end{tabular}




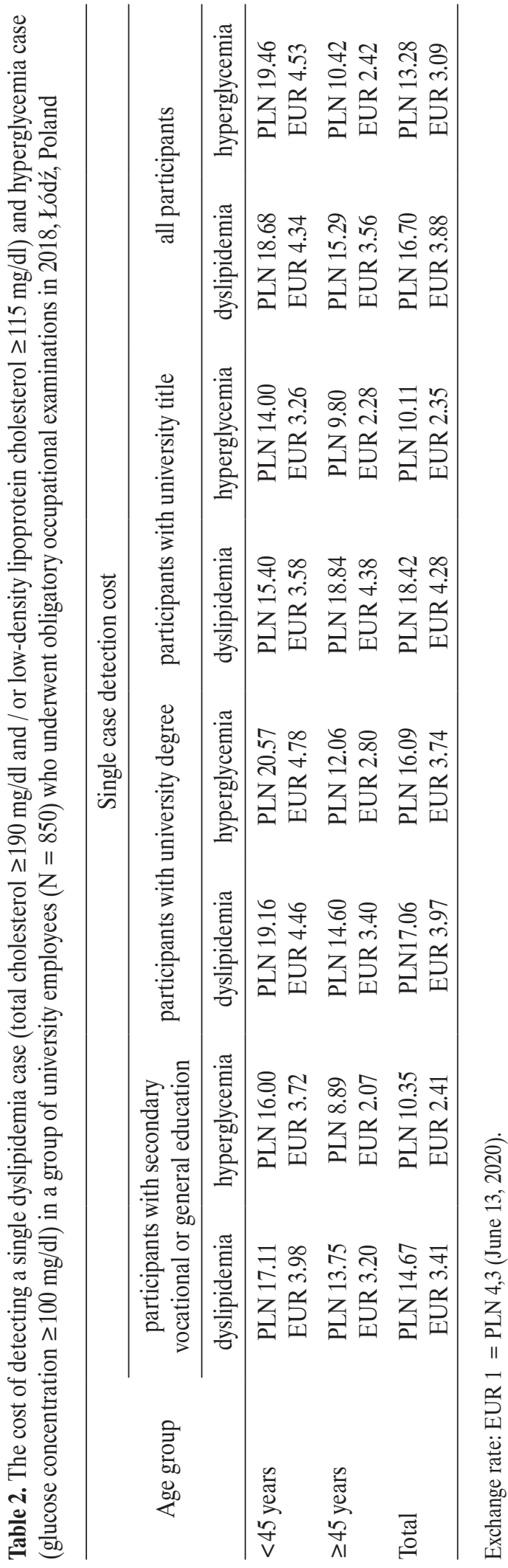

The costs of detecting one case of dyslipidemia or hyperglycemia are presented in Table 2 by education and age. All the study participants (also those previously diagnosed with diabetes) were included in the calculation of the costeffectiveness of detecting a single case of hyperglycemia.

\section{DISCUSSION}

The occupational screening program presented in this paper was based on the obligatory performance of the occupational examination (pursuant to the Polish Labor Code [7]), and additional laboratory lipid profile and glucose tests done in all participants to the study. Considering the administratively imposed obligation to undergo occupational medical examinations, the efficacy of dyslipidemia and hyperglycemia detection in the presented study should be higher than that obtained in the populationbased studies. A beneficial effect of occupational screening tests was also observed by Wilson [8] who indicated a positive influence of the high reporting rate of employee medical check-ups on the profitability analysis. However, the effectiveness of dyslipidemia and hyperglycemia detection depended largely on workers' compliance with the requirement of performing the tests on an empty stomach.

\section{Efficacy of dyslipidemia}

\section{and hypercholesterolemia detection}

The percentage of dyslipidemia cases reported in the study (Table 1) corresponds both to the data on the population aged $20-74$ years $(65.9 \%$ vs. $70 \%)$ and to the data presented by age groups (in the WOBASZ II study, the percentage was $<50 \%$ in males aged $<34$ years; it reached $>70 \%$ in the older age groups; an increase in the incidence of hyperglycemia was also observed in women aged 55-64 years, which was followed by a decrease in older age groups) [9].

The percentage of the diagnosed hyperglycemia cases (Table 1) was significantly higher than in other studies, where the incidence of impaired glucose regulation 
in Europe was at the level of approx. 15\%; impaired fasting glucose (IFG) in adults reached only $10 \%$, and the incidence by age groups was $10.6 \%$ in the group aged $30-65$ years, and $8.9 \%$ in the group aged $>66$ years) [10]. However, the incidence of abnormal glycemia (25.3\%) was similar to the results obtained in the corresponding screening tests on another group of workers in Poland [11]. Interpretation of the obtained results requires considering the risk of non-compliance with the requirement of undergoing the examination on an empty stomach, on the one hand, and the possible underestimation of the incidence of carbohydrate metabolism disorders in the general population, and high unawareness of diabetes (even up to $42 \%$ ), on the other [12].

Scientific literature indicates a positive influence of education on better health indicators [13]. This regularity was also observed in the study presented in this paper with regard to hyperglycemia. An exception was the higher incidence of hyperglycemia in persons with a university title, i.e., in the group of participants to the study with the highest level of education. The reason behind this phenomenon could be risk factors for diabetes related to a long scientific career, such as long working hours and a sedentary lifestyle $[14,15]$.

\section{Cost-effectiveness of dyslipidemia and hyperglycemia detection}

Health and economic benefits of screening tests for hyperlipidemia and hyperglycemia are undeniable. However, there is a discussion about selecting the right target group (the entire population with no preselection or a part of the population that meets additional criteria, such as age or comorbidity criteria), the scope of screening and diagnostic tests, and the frequency of tests. Numerous occupational screening strategies have been presented in the literature on the cost-benefit analysis [8,16,17]. Participation in the occupational medical examination program for senior construction workers showed beneficial results in a 3-year period with regard to workers' levels of lipids, glycated hemoglobin $\mathrm{HbA}_{1 \mathrm{c}}$, blood pressure, nicotinism, and an assessment of the 10-year risk for cardiovascular diseases. In the same study, Welch [16] also observed that physical workers were motivated to improve their health condition when they were given a tailored health program. In turn, Weinhold [18] revealed a positive impact of the health program on university employees.

\section{Age group selection}

A systematic review of 56 studies on the cost-effectiveness of interventions aimed at preventing and controlling diabetes showed the uncertainty of data on cost-benefit in relation to the age of those screened for undiagnosed type 2 diabetes. One study found that cost-effectiveness ratios increased, while another study reported that they decreased with age [19]. In the dyslipidemia management guidelines, the lipid profile screening is recommended in men aged $>40$ years, and in women aged $>50$ years or after the menopause [20]. However, the diabetes management guidelines recommend screening for diabetes every 3 years in patients without risk factors aged $>45$ years, and with selected risk factors every year regardless of age [21]. The studies by Hoerger et al. [22] and Waugh et al. [23] indicate the profitability of targeting diabetes screening tests at specific age groups, as they obtained the highest cost-benefit ratios in the 55-75 years and 40-70 years age groups, respectively.

\section{Target group selection}

In American studies on the detection of diabetes in the population of all ages who were under the care of a primary care physician, profitability rates were more favorable for screening tests in the group of persons with arterial hypertension than for universal screening (without additional criteria) [22]. Apart from hypertension, Waugh et al. [23] noted the greater cost-effectiveness of screening tests aimed at obese persons. Considering the Polish 
screening tests for familial hypercholesterolemia, which also included first job takers, the most cost-effective strategy was the selection of patients after an acute coronary syndrome below 55-65 years of age [17].

\section{Type of screening tests}

The choice of the scope of screening tests aimed at detecting diabetes is also interesting. In a German study conducted by Icks et al. [24], the most effective screening strategy (54\% of detected cases), but also the most expensive one (EUR 21.44 and EUR 31.77 per patient), was the $\mathrm{HbA}_{1 \mathrm{c}}$ test in combination with the oral glucose tolerance test (OGTT). Lower costs were generated by the OGTT alone (EUR 4.90 per patient) and the FPG test in combination with OGTT (EUR 10.85) [24]. In England, based on the multiethnic LEADER population aged 40-74 years, Gillet et al. [25] indicated that it is more cost-effective to perform screening tests for diabetes with the $\mathrm{HbA}_{1 \mathrm{c}}$ test than with the FPG test. However, they observed that in other populations characterized by a higher incidence of diabetes and a higher risk of diabetes, FPG may be more profitable than $\mathrm{HbA}_{1 c}$. In the case of lipid profile screening tests, Berg [36] noted an increased benefit-cost ratio of the complex cardiovascular risk indicators (total cholesterol, high-density lipoprotein [HDL] cholesterol, apolipoprotein A) compared to the total cholesterol alone [26].

\section{Screening frequency}

In a study conducted in Canada, changing the frequency of screening tests for diabetes had little effect on the costeffectiveness rates. However, it was observed that the lack of screening tests with regard to the quality-adjusted life years (QALY) cost the health care system USD 4812 more than the performance of screening tests every 5 years, and the greatest health and financial benefits were achieved when IFG tests were done every 3 years or every year in persons with no prediabetes or with prediabetes, respectively [27]. Brateanu et al. [28] also indicated the benefits of adjusting the screening frequency to the previous test results, and they showed that patients with the high risk of diabetes might be re-tested after 8 months, while patients with relative and low risk might be re-tested after 3 and 5 years, respectively.

\section{Scope of screening tests}

It is worth noting that additional health interventions, besides screening tests, can be beneficial. One-time screening for undiagnosed diabetes and pre-diabetes in young adults in China showed greater cost savings when it was accompanied by appropriate lifestyle interventions among patients with impaired glucose tolerance [29]. A study in America showed that lifestyle interventions in university workers are highly effective in lowering fasting glucose levels [18]. Wilson et al. [8] proved the cost-effectiveness of behavioral interventions aimed at reducing high serum cholesterol in the production population, and they obtained the lowest costs for 1- and 3-month educational interventions.

\section{Implications of screening tests of employees}

Screening tests that go beyond the scope of standard periodic occupational examinations [5], e.g., tests for hypercholesterolemia and hyperglycemia, can be financed by employers using 2 mechanisms. The first one is the subscription fee (flat rate), which gives an employee access to an agreed test package at any time. There is no time limit imposed, and it is voluntary to do the tests. The other mechanism is the one presented in this study and based on the employee's obligation to undergo a periodic occupational examination, during which lipid and fasting glucose profiles are additionally done at the employer's expense. This mechanism translates into a very high reporting rate (100\% in this study). The precondition for performing additional screening tests is an appropriate preparation of the employees concerned, which involves effective notification of the purpose of the examination and the necessity 
to report to the health center on an empty stomach. A solution to this problem could be another more convenient test that does not require fasting, i.e., $\mathrm{HBA}_{1 \mathrm{c}}$, as suggested by Waugh et al. [23]; however, according to the current guidelines, this test is not recommended for the diagnosis of diabetes in Poland [21].

Considering the frequency of occupational examinations, on the one hand, which is determined, e.g., by high fluctuation [4], and cost-effectiveness, on the other hand, which results from the frequency of screening tests [21,27,28], it seems to be an optimal solution to include screening tests for hyperglycemia and dyslipidemia in occupational medical examinations at specific time intervals, e.g., every 3-5 years. However, the condition should be the continuation of preventive care in the same occupational health center or easy access to previous test results, e.g., by means of electronic records.

Based on the results obtained in this study (lower costs of detecting hypercholesterolemia and hyperglycemia) and other studies [20-23], it seems to be justified to preselect the target group with the criterion of age being $>40$ or $>45$ years. It is worth considering additional screening tests for younger persons based on the results of their medical examination (previous test results, identified increased cardiovascular or diabetes risk). Preselection with regard to the job position does not determine better cost-benefit effects, as shown in the case of the costs of hyperglycemia detection in persons with a university title. However, the occupational risk factors for cardiovascular diseases and diabetes, such as occupational stress or shift work, cannot be forgotten [30]. Moreover, it should be noted that the medical screening tests without further intervention are not legitimized. Therefore, after detecting abnormality during periodic examinations, employees should receive further instructions on lifestyle, continuation of diagnosis and possible therapy in primary or specialist health care.

This study is not a prospective study, and the analysis was based on one-time screening tests, which constitutes one of the study limitations, apart from the lack of an in-depth cost-benefit analysis and QALY. However, it is still the first survey in Poland to show the costs incurred by the employer financing additional screening tests within the framework of periodic occupational examinations. It is worth noting that other related costs (e.g., the cost of the employee's absence during the occupational examination or medical consultations) should not be treated as a separate cost of screening tests, as they have already been included in the costs of obligatory periodic examinations. This seems to be an advantage of doing screening tests as a part of other examinations, such as periodic occupational examinations.

\section{CONCLUSIONS}

Due to the fact that the reporting rate for screening tests in the framework of occupational medicine is high, the cost of occupational screening tests for dyslipidemia and hyperglycemia can be lower than the cost of screening tests in the general population.

\section{REFERENCES}

1. Baicker K, Cutler D, Song Z. Workplace wellness programs can generate savings. Health Aff (Millwood). 2010;29(2):30411, https://doi.org/10.1377/hlthaff.2009.0626.

2. International Social Security Association. Calculating the international return on prevention for companies: costs and benefits of investments in occupational safety and health [Internet]. Geneva: The Association; 2013 [cited 2020 Jun 20]. Available from: https:/ww1.issa.int/sites/default/files/documents/publications/2-ROP-FINAL_en-157255.pdf.

3. Supreme Audit Office. [Health promotion and disease prevention in the health care system. Information on the inspection results] [Internet]. Warszawa: The Office; 2017 [cited 2020 May 8]. Available from: https://bip.nik.gov.pl/kontrole/ wyniki-kontroli-nik/kontrole,16703.html. Polish.

4. Marcinkiewicz A. [Resources and activities of occupational health services in Poland. Analysis of mandatory medical reporting for years 2014-2108]. Med Pr. 2020;71(4):429-41, https://doi.org/10.13075/mp.5893.00982. Polish. 
5. [Regulation of the Minister of Health and Social Care of 30 May 1996 on the medical examinations of employees, the scope of occupational preventive health care and medical certifications for purposes of the Labour Code. J Laws 2016, item 2067]. Polish.

6. Szymański FM, Barylski M, Cybulska B, WożakowskaKapłon B, Krasiński Z, Mamcarz A, et al. Recommendation for the management of dyslipidemia in Poland - Third Declaration of Sopot. Interdisciplinary Expert Position Statement endorsed by the Polish Cardiac Society Working Group on Cardiovascular Pharmacotherapy. Cardiol J. 2018;25(6):65565, https://doi.org/10.5603/CJ.2018.0141.

7. [The Labour Code. J Laws 2019, item 1040]. Polish.

8. Wilson MG, Edmunson J, DeJoy DM. Cost Effectiveness of Work-Site Cholesterol Screening and Intervention Programs. J Occup Med. 1992;34(6):642-9.

9. Pająk A, Szafraniec K, Polak M, Polakowska M, Kozela M, Piotrowski W, et al. on behalf of WOBASZ II investigators. Changes in the prevalence, treatment, and control of hypercholesterolemia and other dyslipidemias over 10 years in Poland: the WOBASZ study. Pol Arch Med Wewn. 2016; 126(9):642-52, https://doi.org/10.20452/pamw.3464.

10. Eades CE, France EF, Evans JMM. Prevalence of impaired glucose regulation in Europe: a meta-analysis. Eur J Public Health. 2016;26:699-706, https://doi.org/10.1093/eurpub/ckw085.

11. Marcinkiewicz A, Hanke W, Kałużny P, Lipińska-Ojrzanowska A, Wiszniewska M, Walusiak-Skorupa J. Can periodical examinations of employees be useful in detection of glycaemia impairment and improving patients' adherence to medical recommendations? Int J Environ Res Public Health. 2018;15:638, https://doi.org/10.3390/ijerph15040638.

12. The International Diabetes Federation. IDF Diabetes Atlas - 9th Edition [Internet]. Brussels: The Federation; 2019 [cited 2020 Jul 16]. Available from: https://diabetesatlas.org/data/en/indicators/4/.

13. Ostrowska A. [Psychosocial determinants of health inequalities]. Zdr Publ Zarz. 2011;2:55-63, https://doi.org/10.4467/ 20842627OZ.11.001.0338.
14. Wilmot EG, Edwardson CL, Achana FA, Davies MJ, Gorely T, Gray LJ, et al. Sedentary time in adults and the association with diabetes, cardiovascular disease and death: systematic review and meta-analysis. [published correction appears in Diabetologia. 2013;56(4):942-3]. Diabetologia. 2012;55(11):2895-905, https://doi.org/10.1007/s00125-012-2677-z.

15. Kivimäki M, Virtanen M, Kawachi I, Nyberg ST, Alfredsson L, Batty GD, et al. Long working hours, socioeconomic status, and the risk of incident type 2 diabetes: a meta-analysis of published and unpublished data from 222120 individuals. Lancet Diabetes Endocrinol. 2015;3(1):27-34, https:// doi.org/10.1016/S2213-8587(14)70178-0.

16. Welch LS, Dement J, Ringen K, Cranford K, Quinn PS. Impact of Secondary Prevention in an Occupational High-Risk Group. J Occup Environ Med. 2017;59(1):67-73, https://doi. org/10.1097/JOM.0000000000000925.

17. Pelczarska A, Jakubczyk M, Jakubiak-Lasocka J, Banach M, Myśliwiec M, Gruchała M, et al. The cost-effectiveness of screening strategies for familial hypercholesterolaemia in Poland. Atherosclerosis. 2018;270:132-8, https://doi.org/10. 1016/j.atherosclerosis.2018.01.036.

18. Weinhold KR, Miller CK, Marrero DG, Nagaraja HN, Focht BC, Gascon GM. A Randomized Controlled Trial Translating the Diabetes Prevention Program to a University Worksite, Ohio, 2012-2014. Prev Chronic Dis. 2015;12:E210, https://doi.org/10.5888/pcd12.150301.

19. Li R, Zhang P, Barker LE, Chowdhury FM, Zhang X. Cost-Effectiveness of Interventions to Prevent and Control Diabetes Mellitus: A Systematic Review. Diab Care. 2010; 33(8):1872-94, https://doi.org/10.2337/dc10-0843.

20. Mach F, Baigent C, Catapano AL, Koskinas KC, Casula M, Badimon L, et al. ESC Scientific Document Group, 2019 ESC/EAS Guidelines for the management of dyslipidaemias: lipid modification to reduce cardiovascular risk: The Task Force for the management of dyslipidaemias of the European Society of Cardiology (ESC) and European Atherosclerosis Society (EAS). Eur Heart J. 2020;41(1):111-88, https:// doi.org/10.1093/eurheartj/ehz455. 
21. 2020 Guidelines on the management of diabetic patients. A position of Diabetes Poland. Clin Diabetol. 2020;9(1):1-101, https://doi.org/10.5603/DK.2020.0001.

22. Hoerger TJ, Harris R, Hicks KA, Donahue K, Sorensen S, Engelgau M. Screening for type 2 diabetes mellitus: a costeffectiveness analysis. Ann Intern Med 2004;140:689-99, https://doi.org/10.7326/0003-4819-140-9-200405040-00008.

23. Waugh N, Scotland G, McNamee P, Gillett M, Brennan A. Screening for Type 2 Diabetes: literature review and economic modelling. Health Technol Assess. 2007;11(17):iii-125, https://doi.org/10.3310/hta11170.

24. Icks A, Haastert B, Gandjour A, John J, Löwel H, Holle R, et al. on behalf of the KORA Study Group. Cost-effectiveness analysis of different screening procedures for type-2-diabetes: the KORA Survey 2000. Diab Care. 2004;27:2120-8, https://doi.org/10.2337/diacare.27.9.2120.

25. Gillett M, Brennan A, Watson P, Khunti K, Davies M, Mostafa S, et al. The cost-effectiveness of testing strategies for type 2 diabetes: a modelling study. Health Technol Assess. 2015;19(33):1-80, https://doi.org/10.3310/hta19330.

26. Berg JE. Screening for cardiovascular risk: cost-benefit considerations in a comparison of total cholesterol measurements and two compound blood lipid indices. J Cardiovasc Risk. 1995;2(5):441-7,https://doi.org/10.1177/174182679500200509.

27. Mortaz S, Wessman C, Duncan R, Gray R, Badawi A. Impact of screening and early detection of impaired fasting glucose tolerance and type 2 diabetes in Canada: a Markov model simulation. Clinicoecon Outcomes Res. 2012;4:91-7, https://doi.org/10.2147/CEOR.S30547.

28. Brateanu A, Barwacz T, Kou L, Wang S, Misra-Hebert Ad, $\mathrm{Hu} \mathrm{B}$, et al. Determining the optimal screening interval for type 2 diabetes mellitus using a risk prediction model. PLoS One. 2017;12(11):e0187695, https://doi.org/10.1371/journal. pone. 0187695 .

29. Liu X, Li C, Gong H, Cui Z, Fan L, Yu W, et al. An economic evaluation for prevention of diabetes mellitus in a developing country: a modelling study. BMC Public Health. 2013;13,729, https://doi.org/10.1186/1471-2458-13-729.

30. Garbarino S, Magnavita N. Work Stress and Metabolic Syndrome in Police Officers. A Prospective Study. PLoS ONE 2015;10(12):e0144318, https://doi.org/10.1371/journal. pone. 0144318 .

This work is available in Open Access model and licensed under a Creative Commons Attribution-NonCommercial 3.0 Poland License - http://creativecommons.org/ licenses/by-nc/3.0/pl/deed.en. 